\title{
Effects of Peroxisome Proliferator-Activated Receptor Ligand and Brown Seaweed Based Compound on Megakaryocyte
}

\author{
Jae-Lim Choi,, Ri-Young Goh, ${ }^{1}$ Seong-Hoon Yun, ${ }^{3}$ Joo-In Park, Jin-Yeong Han ${ }^{2}$ \\ 'Department of Laboratory Medicine, Seegene Medical Foundation, Busan, Korea \\ 2Departments of Laboratory Medicine and ${ }^{3}$ Biochemistry, Dong-A University College of Medicine, Busan, Korea
}

Received: 21 November 2018

Revised: 21 January 2019

Accepted: 15 February 2019

*Corresponding author: Jin-Yeong Han

Department of Laboratory Medicine Dong-A University College of Medicine, 26 Daesingongwon-ro, Seo-gu,

Busan 49201, Korea

Tel: $+82-51-240-5323$

Fax: +82-51-255-9366

E-mail: jyhan@dau.ac.kr
Copyright () Korean Society on Thrombosis and Hemostasis. All rights reserved.

\begin{abstract}
Purpose: The ligand-activated transcription factor peroxisome proliferator-activated receptor (PPAR)y has been reported to promote the formation of platelets from megakaryocytes and accelerate platelet recovery. The endogenous prostaglandin 15-deoxy- $\Delta 12,14$ prostaglandin $J_{2}\left(15 d-P G J_{2}\right)$ is a ligand of PPAR $\gamma$. Fucoidans are constituents of brown seaweed, and their anticoagulant and antithrombotic actions are recognized. In this study, we analyzed how PPAR ligand and brown seaweed based compound affect megakaryocyte and platelet in vitro.

Methods: Platelets were isolated from discarded plateletpheresis products by centrifugation. We used DAMI and Meg-01 cells as well. We treated these cells with 15d-PGJ2, GW9662, fucoidan, GW6471, and celecoxib. Then their effects on platelet membrane glycoproteins and PPAR $\gamma$, PPAR $\alpha$ and COX-2 expression, thrombogenicity and genetic regulation were analyzed.

Results: $15 \mathrm{~d}-\mathrm{PG} \mathrm{J}_{2}$ induced megakaryocytic differentiation evidence in morphology and flow cytometry analysis. In microarray analysis, fucoidan showed early growth response 1 (EGR1), Fc receptor, IgG, high affinity 1 (FCGR1), YME1 like 1 ATPase (YME1L1), stanniocalcin 1 (STC1) and cytochrome P450 family 11 subfamily B member 2 (CYP11B2) genes upregulation on megakaryocytes.

Conclusion: These findings support PPAR ligand, and brown seaweed based compound plays a role in megakaryocytic differentiation even in genomic level.
\end{abstract}

Keywords: Megakaryocytes, Platelet, PPAR ligand, Fucoidan

\section{Introduction}

Platelets are anuclear cells released from megakaryocytes, the rare myeloid cells that undergo multiple rounds of endomitosis before releasing platelets. Platelets, known as the mediator of thrombosis, are emerging as cellular mediators of type II diabetes, atherosclerosis, cancer cell metastasis, and immune responses. ${ }^{1,2}$ Despite the lack of a nucleus, they express a large number of transcription factors including peroxisome proliferator-activated receptor (PPAR). PPAR needs ligand-binding to be activated. ${ }^{3}$

PPAR, a ligand-activated transcription factor, consists of 3 isoforms: $\alpha, \beta / \delta, \gamma$, and requires heterodimerization with retinoid $\mathrm{X}$ receptor to modulate transcription of target genes. ${ }^{4}$ PPAR $\gamma$ is involved in glucose metabolism, inflammation, and differentiation and functions of adipose tissue. ${ }^{5-7}$ Recent studies have reported that the PPAR $\gamma$ inhibits platelet activation and aggregation. ${ }^{8-11}$ Also, studies have reported the PPAR $\gamma$ and ligand of PPAR $\gamma$ as the factor influences the hematopoietic system. They could affect the roles of erythroid, myeloid, monocytic, and lymphocytic cell function during an immune response, and modulate proliferation and maturation of erythroid progenitor cells. ${ }^{12-14}$ The endogenous 15 -deoxy- $\Delta^{12,14}$ prostaglandin $\mathrm{J}_{2}\left(15 \mathrm{~d}-\mathrm{PGJ}_{2}\right)$ is a ligand of PPAR $\gamma$. Biologically, $15 \mathrm{~d}-\mathrm{PGJ}_{2}$ is the most active metabolite of prostaglandin $\mathrm{D}_{2}{ }^{15}$

Fucoidans, fucose-containing sulfated polysaccharides, are constituents of brown seaweed and some marine invertebrates. Extensive studies have reported their various biological effects including immunostimulation, anti-tumor, antiviral, antithrombotic and anticoagulant activities. By far the anticoagulant and antithrombotic actions of fucoidans are the most widely recognized bioactivities, but the basis for these activities is not completely understood. ${ }^{16-19}$

We are interested in the influences of $15 \mathrm{~d}-\mathrm{PGJ}_{2}$ and fucoidans to the megakaryocytic differentiation and the platelet production, as well as the influences of $15 \mathrm{~d}-\mathrm{PGJ}_{2}$ and fucoidans to the thrombosis and coagulation system. Due to their antithrombotic and anticoagulant activities, they have the probability of the application as the novel therapeutic agents to cardiovascular disease. Also, if they have the abilities inducing the production of platelet, they could be the stable solution of platelet supply to the thrombocytopenic patients.

In this study, we evaluated the effects of $15 \mathrm{~d}-\mathrm{PGJ}_{2}$ and fucoidans on megakaryocytes and platelets with diverse methods from protein to the molecular level. This study aims to determine 1) whether the $15 \mathrm{~d}-\mathrm{PGJ}_{2}$ and fucoidans encourage the megakaryocytes to produce platelets actively; 2) whether the $15 \mathrm{~d}-\mathrm{PGJ}_{2}$ and fucoidans possess the anticoagulant and antithrombotic actions, and 3) whether specific factors, such as prostaglandins or genes, explain the mechanism of how the $15 \mathrm{~d}-\mathrm{PGJ}_{2}$ and fucoidans influence differentiation and function of the platelets. To search these factors, we also included PPAR $\alpha$, which activates fatty acid catabolism and stimulates gluconeogenesis, attenuates inflammatory responses, and participates in the amino acid metabolism, and COX-2, which is responsible for the formation of prostanoids, including thromboxane and prostaglandins such as prostacyclin, from arachidonic acid. 


\section{Methods}

Platelet isolation

Platelets were isolated from discarded plateletpheresis products by centrifugation at $1,800 \mathrm{~g}$ for 8 minutes at room temperature. $\mathrm{CBC}$ with platelet count was done using Sysmex XE-2100 automated hematology system (Sysmex Corporation, Japan). On average, we obtained $1.3 \times 10^{6} / \mu \mathrm{L}$ platelets for the experiment, and the platelet purity was greater than $99 \%$.

\section{Cell culture}

We purchased the human megakaryocytic DAMI cell lines and human megakaryoblastic Meg-01 cell lines from Sigma company (Balcatta, WA). DAMI and Meg-01 cells were cultured in RPMI-1640 tissue culture medium (Invitrogen, Carlsbad, CA) supplemented with $5 \%$ fetal bovine serum (FBS; Invitrogen).

Platelet, DAMI and Meg-01 cells treatment

We treated platelets, DAMI, and Meg-01 cells with $10 \mu \mathrm{M} 15 \mathrm{~d}-$ $\mathrm{PGJ}_{2}$ (PPAR $\gamma$ ligand), $20 \mu \mathrm{M}$ GW9662 (PPAR $\gamma$ antagonist), and 50 $\mu \mathrm{g} / \mathrm{mL}$ fucoidan for 24 hours.

We also treated platelets with $50 \mu \mathrm{g} / \mathrm{mL}$ fucoidan to examine the expression of PPAR $\alpha$ and COX-2 in the presence or absence of 0.25 $\mu \mathrm{M}$ GW6471 (PPAR $\alpha$ antagonist) and $0.04 \mu \mathrm{M}$ celecoxib (COX-2 inhibitor) for 24 hours.
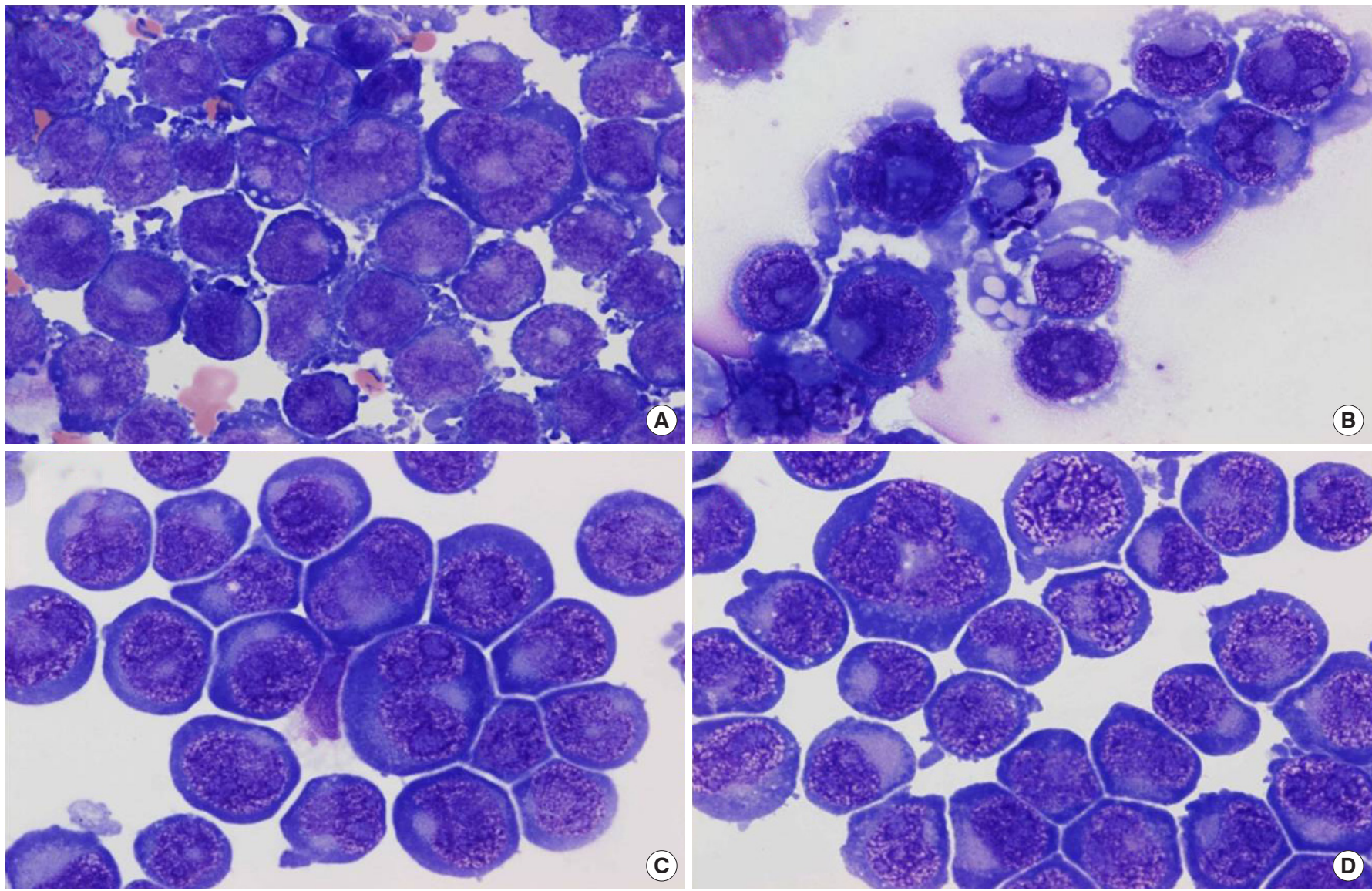

Microscopic observation

Cytospin smears of DAMI and Meg-01 cells were stained with Wright-Giemsa and examined after each experiment. To investigate the megakaryocytic differentiation and platelet formation effect of $15 \mathrm{~d}$ $\mathrm{PGJ}_{2}$, GW9662, and fucoidan on the DAMI cells, we observed the morphology of those cells with an optical microscope.

Flow cytometry

Platelets, DAMI, and Meg-01 cells were identified using CD61 (glycoprotein IIIa) antibody. They were analyzed by staining with CD41 (glycoprotein IIb/IIIa), CD42b (glycoprotein Ib), CD62p (P-selectin), CD63 (platelet activation marker) and PAC-1 antibodies and using a Coulter Navios flow cytometer (Beckman Coulter, USA). Data acquisition and analysis were performed using Kaluza analysis software (Beckman Coulter, USA).

\section{Western blotting}

We extracted proteins by a standard technique, ${ }^{8}$ and diluted aliquots (30 $\mu \mathrm{g}$ ) with $4 \times$ Loading buffer (Invitrogen, USA), heated at $95^{\circ} \mathrm{C}$ for 5 minutes and fractionated by $8 \%$ polyacrylamide gel electrophoresis. To compare the expression of PPAR $\gamma, \operatorname{PPAR} \alpha$ and COX-2 in human megakaryocytes and platelets, the 1:2,000 diluted primary goat antibody and rabbit anti-goat antibody were used, respectively, for 2 hours at room temperature. Membranes were visualized with chemiluminescence.

Fig. 1. Morphology of DAMI cells. (A) Negative control with no treatment. (B) 15d-PGJ2-treated DAMI cells. (C) BW9662-treated DAMI cells. (D) Fucoidan-treated DAMI cells (Wright-Giemsa stain; original magnification $\times 1,000$ ). 
Thrombus formation analysis

Total thrombogenicity of platelets treated with fucoidan was measured by T-TAS (Total Thrombus-formation Analysis System; Fujimori Kogyo, Japan). The system is developed for the quantitative assessment of the platelet thrombus formation (PTF) process. There are two types of the microchip, "PL-chip" and "AR-chip" for evaluating "platelet-specific" and "comprehensive" thrombus formation, respectively. When blood flows through the chip, the platelet aggregates gradually increase the flow pressure. In PTF-assay, the parameter AUC (area under the flow pressure curve) represents total thrombogenicity.

Microarray analysis

The effect of fucoidan on DAMI cells was evaluated with microarray analysis. We used $100 \mathrm{ng}$ of total RNA for generation of biotinlabeled cRNA using Affymetrix Two-Cycle cDNA Synthesis Kit (Affymetrix, Santa Clara, CA). The labeled cRNA was cleaned, quantified and after fragmentation, hybridized to Affymetrix HG-U133 Plus2.0 GeneChips. The chips were stained with streptavidin-phycoerythrin and biotinylated antibody and washed at an Affymetrix Fluidics station 450. The GeneChips were scanned and data extracted using GeneChip scanner 3000 (Affymetrix, Santa Clara, CA), and the raw data file formats were generated using GeneChip operating software (GCOS).
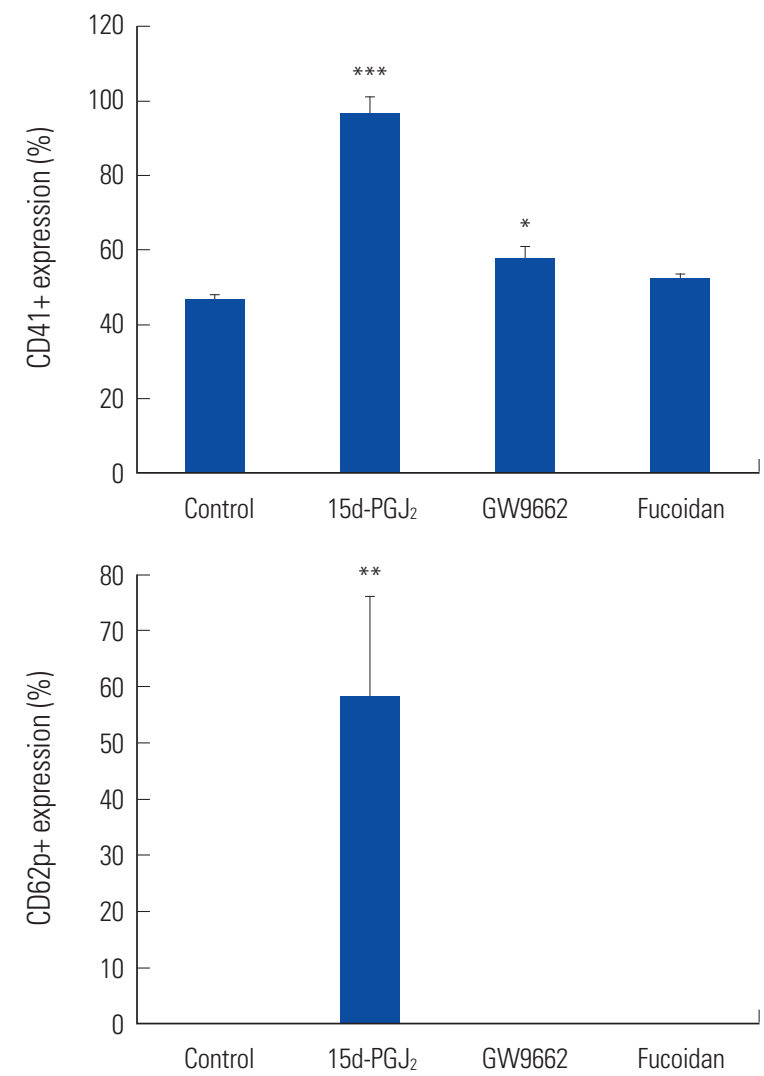

Statistical methods

Results were expressed as the mean with standard deviation. Statistical analysis of the data was performed by ANOVA using SPSS version 21.0. $P$-values of less than 0.05 were regarded as significant.

\section{Results}

The effect of $15 \mathrm{~d}-\mathrm{PGJ}_{2}$ (PPAR $\gamma$ ligand) on megakaryocytes We have demonstrated that $15 \mathrm{~d}-\mathrm{PGJ}_{2}$ induced morphological differentiation in DAMI cells, reflective of megakaryocyte maturation. $15 \mathrm{~d}-\mathrm{PGJ}_{2}$-treated DAMI cells showed the smaller size of nuclei and a more abundant amount of cytoplasm with less basophilic color, suggesting differentiation evidence (Fig. 1).

Increased levels of CD41, CD42b, CD62p, and PAC-1 by $15 \mathrm{~d}-$ $\mathrm{PGJ}_{2}$ in DAMI cells also indicate differentiation of megakaryocytes into mature cells. $15 \mathrm{~d}-\mathrm{PGJ}_{2}$ increased the levels of CD41 $(P=0.0004)$, CD42b $(P=0.0008)$, CD62p $(P=0.004)$ and PAC-1 $(P=0.001)$ significantly in DAMI cells, respectively (Fig. 2).

$15 \mathrm{~d}-\mathrm{PGJ}_{2}$ had no significant effects on the expression of PPAR $\gamma$ in megakaryocytes. In DAMI cells, $15 \mathrm{~d}_{-} \mathrm{PGJ}_{2}$ decreased COX-2 expression ( 0.559 fold, $P<0.01)$ than control (Fig. 3).

The effect of GW9662 (PPAR $\gamma$ antagonist) on megakaryocytes Treatment with GW9662, the irreversible PPAR $\gamma$ antagonist, induced a few specific changes. GW9662-treated DAMI cells showed no
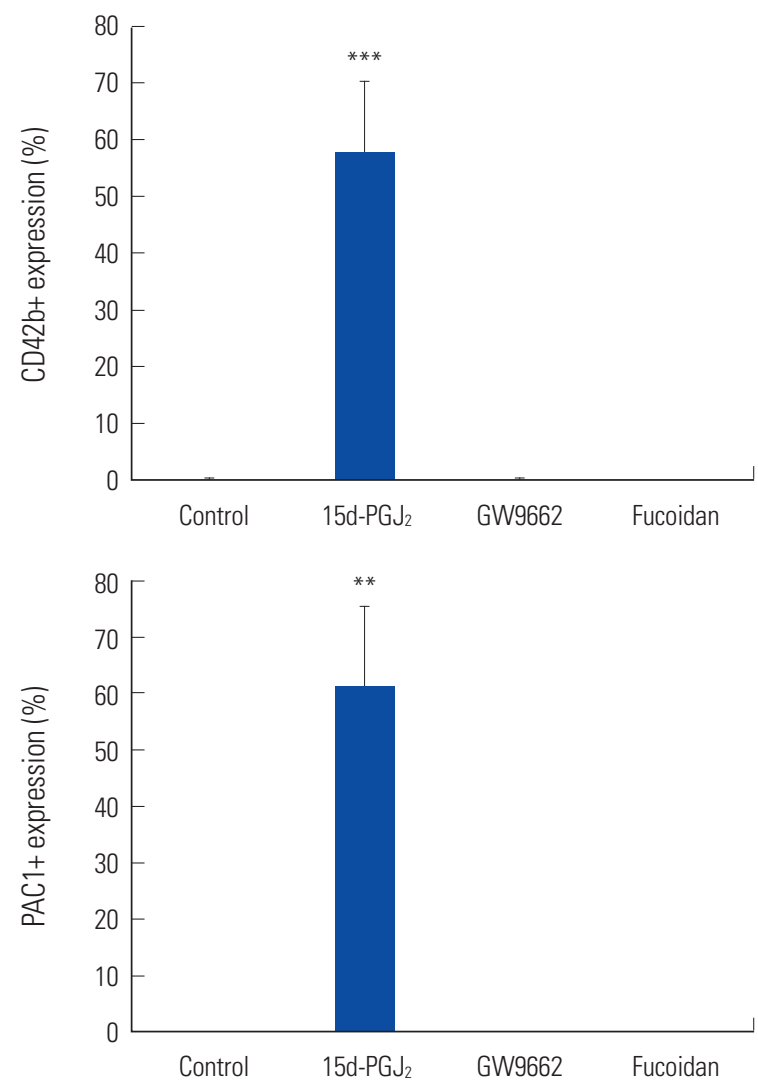

Fig. 2. Results of flow cytometry analysis in megakaryocyte. $15 d-P G J_{2}$ increased the levels of CD41 ( $\left.P=0.0004\right)$, CD42b $(P=0.0008), C D 62 p(P=0.004)$ and $P A C-1$ $(P=0.001)$ significantly in DAMl cells, respectively. Except for significantly increased level of CD41 $(P=0.039)$, GW9662 had no significant effect on the level of glycoproteins, especially on CD42b, CD62p, and PAC-1 in DAMI cells. Fucoidan had no significant effect on glycoproteins in DAMI cells. ${ }^{*} P<0.05$; ${ }^{* *} P<0.01$; ${ }^{* *} P<0.001$ by the ANOVA. 

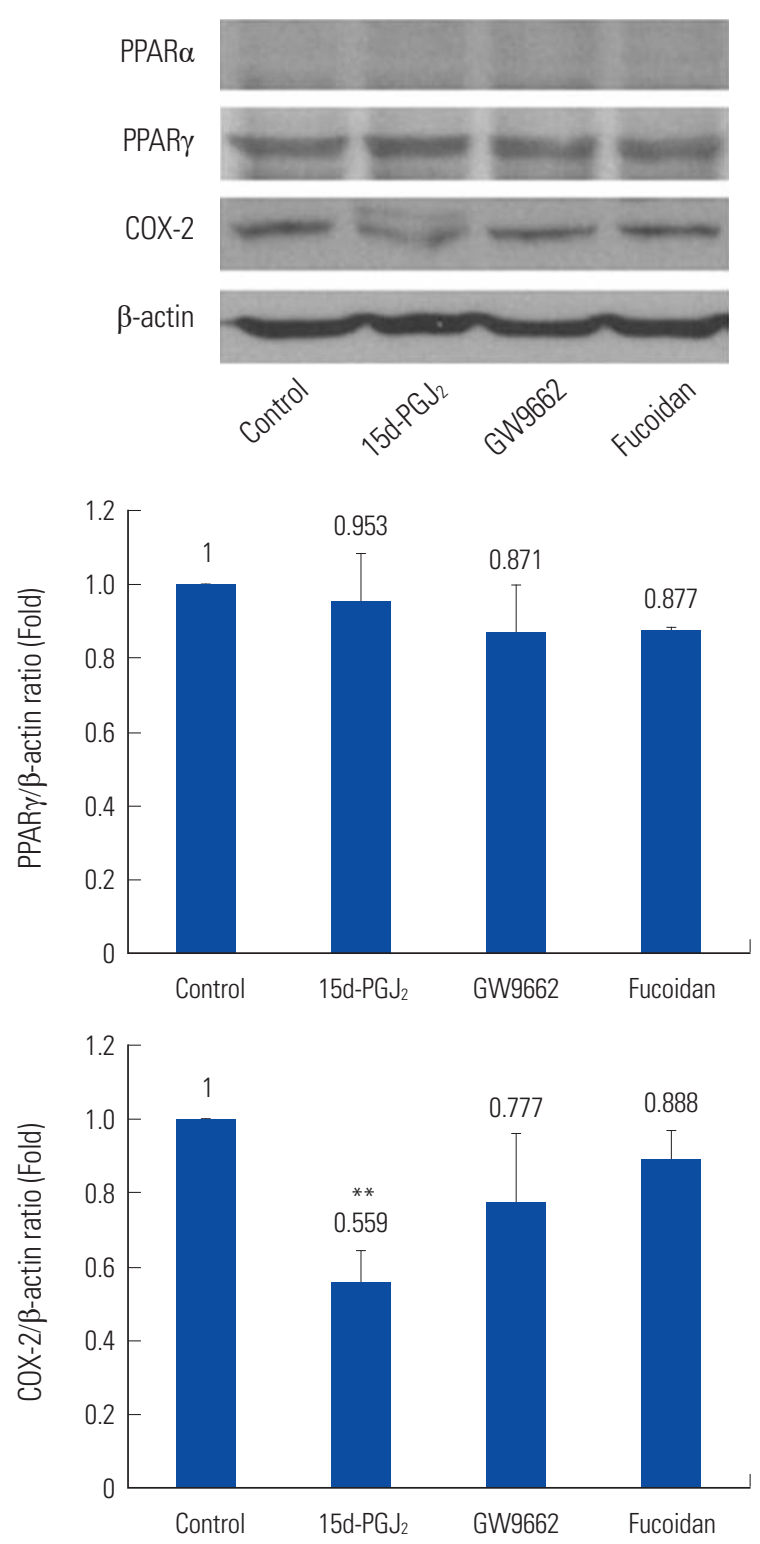

Fig. 3. Results of Western blotting analysis in megakaryocyte. 15d-PG $J_{2}$ had no significant effects on the expression of PPAR $\gamma$ in DAMI cells. 15d-PGJ2 decreased COX-2 expression ( 0.559 fold, $P<0.01$ ) than control. GW9662 and fucoidan had no significant effects on the expression of PPAR $\gamma$, PPAR $\alpha$, and COX-2. ${ }^{* *} P<0.01$.

specific morphological changes, although gave lower $\mathrm{N}$ (nucleus)/C (cytoplasm) ratio as compared to the control (Fig. 1).

Except for significantly increased level of CD41 ( $P=0.039)$, GW9662 had no significant effect on the level of glycoproteins, especially on CD42b, CD62p, and PAC-1 in DAMI cells (Fig. 2).

In the Western blotting to compare the expression of PPAR $\gamma$, PPAR $\alpha$, and COX-2, GW9662 had no significant effects (Fig. 3).

The effect of fucoidan on megakaryocytes

We also evaluated the effect of fucoidan on the platelet differentiation. We expected fucoidan has an effect on the production of platelets, but we could not observe any morphological changes as $15 \mathrm{~d}-$ $\mathrm{PGJ}_{2}$ (Fig. 1).
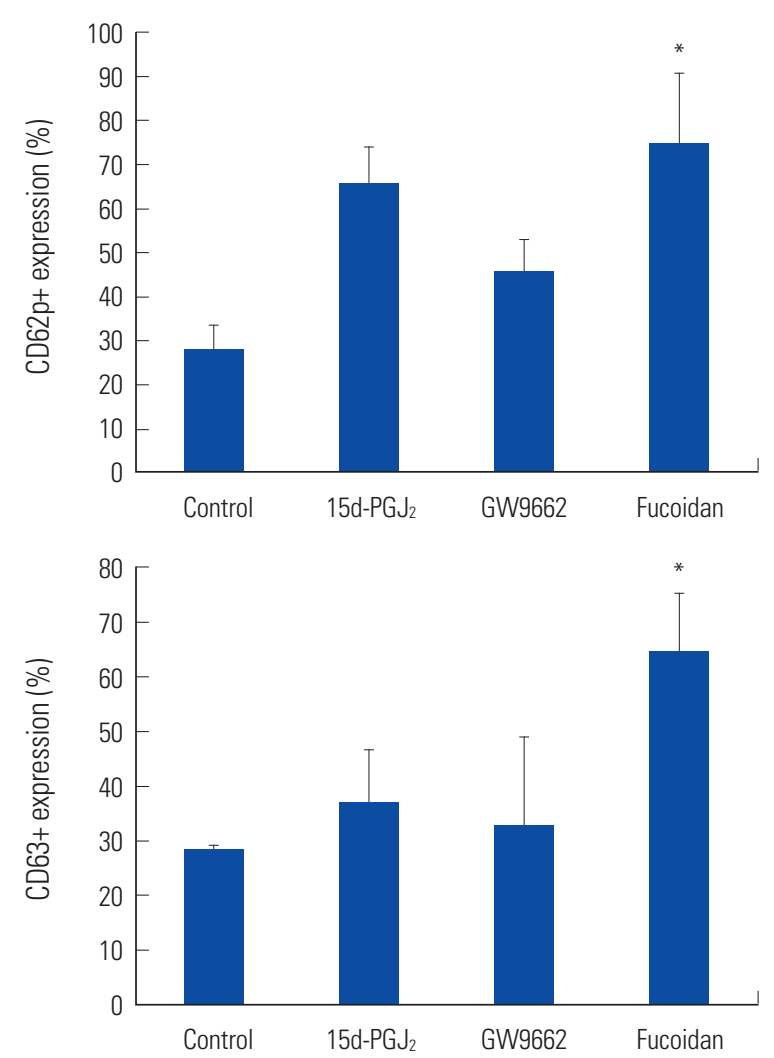

Fig. 4. Results of flow cytometry analysis in mature platelet. Fucoidan elevated the expression of CD62p $(P=0.033)$ and $\operatorname{CD63}(P=0.036)$ significantly. ${ }^{*} P<0.05$.

Additionally, fucoidan had no significant effect on CD41, CD42b, CD61, CD62p, CD63, and PAC-1 in DAMI cells (Fig. 2).

Fucoidan had no significant effects on megakaryocytes in the Western blotting to compare the expression of PPAR $\gamma$, PPAR $\alpha$, and COX2 (Fig. 3).

The effect of fucoidan on DAMI cells was evaluated with microarray analysis. As results, 17 transcript clusters were differentially expressed $(P<0.05)$ at a $>2.0$ fold change. Among the clusters, five clusters were mapped to a valid gene, the early growth response 1 $(E G R 1), \mathrm{Fc}$ receptor, IgG, high affinity 1 (FCGRI), YME1 like 1 ATPase (YME1L1), stanniocalcin 1 (STC1) and cytochrome P450 family 11 subfamily B member 2 (CYP11B2).

The effect of 15d-PGJ ${ }_{2}$ and GW9662 on mature platelets $15 \mathrm{~d}-\mathrm{PGJ}_{2}$ and GW9662 showed no significant effects in mature platelets.

The effect of fucoidan on mature platelets In flow cytometry analysis, fucoidan elevated the expression of CD$62 p(P=0.033)$ and CD63 $(P=0.036)$ significantly (Fig. 4).

In mature platelets, fucoidan decreased PPAR $\alpha$ expression $(0.192$ fold, $P=0.014$ ), and increased COX-2 expression (2.308 fold, $P=$ 0.218) than control (Fig. 5).

Fucoidan increased COX-2 expression in combination with GW6471 ( 2.115 fold, $P=0.109$ ), and combination with celecoxib (2.97 fold, $P=0.099)$ than control.

PTF-assay with T-TAS was performed. In the study with PL-chip, 

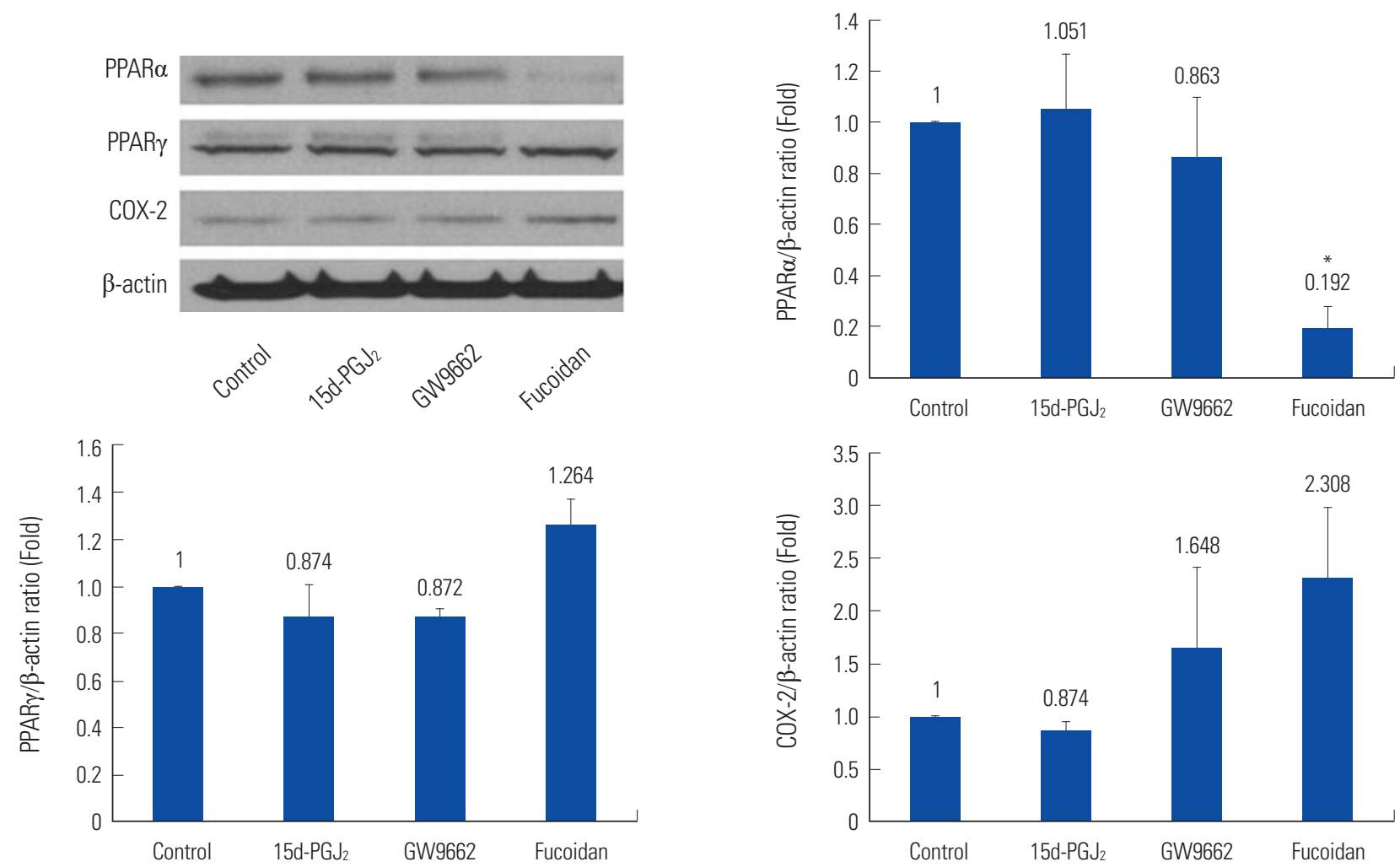

Fig. 5. Results of Western blotting analysis in mature platelet. Fucoidan decreased PPAR $\alpha$ expression (0.192 fold, $P=0.014)$, and increased COX-2 expression (2.308 fold, $P=0.218$ ) than control. ${ }^{*} P<0.05$.

AUC of GW6471 (43.5) was wider than control (28.35) $(P=0.970)$, AUC of fucoidan (8.55) was narrower than control $(P=0.916)$, and AUC of celecoxib (28.85) was similar with control $(P=1.000)$. In the study with AR-chip, AUC of GW6471 (44.7) was wider than control (38.1) $(P=0.998)$, AUC of celecoxib (28.75) and fucoidan (27.4) was narrower than control ( $P=0.992, P=0.985$, respectively).

\section{Discussion}

Megakaryocytes are the biggest cell of the bone marrow, and platelets are derived from the cytoplasm of megakaryocytes. Platelets are metabolically active cellular mediators of various vascular biology containing copious amounts of bioactive materials including thromboxanes, prostaglandins, chemokines, and cytokines. Besides their crucial function of initiating thrombosis and maintaining hemostasis, platelets are also revealed as key mediators of inflammation and immune cell activation. ${ }^{1,2}$

While the clear importance of the platelets in various conditions and diseases has been emerging, diverse proteins to be expressed or released from platelets have been identified through proteomics. Although mature platelets are anucleated, they were discovered to express a large number of transcription factors including PPAR which is involved in the regulation of metabolism and inflammation and regulated by activation or treatment with PPAR ligands. ${ }^{3}$ PPAR $\gamma$ ligands have been suggested to influence platelet production and function.

There are researches aimed to reveal the functions of the PPAR and ligand of PPAR influencing the hematopoietic system. The interesting thing is that the reports mentioned it is unclear if the PPAR $\gamma$ itself modulates the differentiation of megakaryocytes, whereas the PPAR $\gamma$ ligand enhances platelet production from megakaryocytes. ${ }^{12,14}$ In our study, $15 \mathrm{~d}-\mathrm{PGJ}_{2}$ induced morphological differentiation in DAMI and Meg-01 cells, reflective of megakaryocyte maturation. Increased levels of CD41, CD42b, CD62p, and PAC-1 by $15 \mathrm{~d}-\mathrm{PGJ}_{2}$ in DAMI and Meg-01 cells also indicate differentiation of megakaryocytes into mature cells and platelet release. These results suggest $15 \mathrm{~d}-\mathrm{PGJ}_{2}$ could lead to enhanced platelet production. However, we couldn't conclude it is dependent on the PPAR $\gamma$ because of the effects of GW9662, the PPAR $\gamma$ antagonist, on megakaryocytes. Although it induced a few changes on the morphology and flow cytometry analysis, the lower $\mathrm{N}$ (nucleus)/C (cytoplasm) ratio of megakaryocytes and significantly increased the level of CD41 indicate GW9662 could influence the differentiation of megakaryocytes slightly. So, the effects of $15 \mathrm{~d}-\mathrm{PGJ}_{2}$ on megakaryocytes are clear, but the probability of intermediation of PPAR $\gamma$ is somewhat lower.

$15 \mathrm{~d}-\mathrm{PGJ}_{2}$ significantly decreased COX-2 expression of megakaryocytes. A study suggested $15 \mathrm{~d}_{-} \mathrm{PGJ}_{2}$ use both receptor-dependent and -independent mechanisms to influence $C O X 2$ gene expression. ${ }^{20}$ In the study, it was observed that $C O X 2$ expression was significantly abrogated by $15 \mathrm{~d}-\mathrm{PGJ}_{2}$. But they made an experiment on the influence of $15 \mathrm{~d}-\mathrm{PGJ}_{2}$ in Human WISH, the cells originated from amniotic sac, and amnion cells, further studies using megakaryocytes would be helpful to understand the precise mechanisms.

In our study, fucoidan had no significant effect on megakaryocytes in morphology, flow cytometry analysis, and Western blotting. But in the microarray analysis, the five genes were significantly upregulated in fucoidan-treated DAMI cells. The protein encoded by $E G R 1$ is a nuclear protein and functions as a transcriptional regula- 
tor. FCGR, the receptors for the Fc region of $\mathrm{IgG}$, is expressed by leukocytes and platelets. YME1L1 encodes the human ortholog of yeast mitochondrial AAA metalloprotease Ymelp, which has been proposed that the gene plays a role in mitochondrial protein metabolism. STC1 is a homodimeric glycoprotein that may play a role in the regulation of calcium and phosphate transport and cell metabolism. STC1 gene expression has altered in tumors. CYP11B2 encodes a member of the cytochrome P450 superfamily of enzymes, which synthesize aldosterone.

EGR1 has been reported to contribute to suppression of PPAR $\gamma$ expression. ${ }^{21}$ To know the more accurate mechanism related to the $\operatorname{PPAR} \gamma$, the microarray analysis using ago- and antagonists of PPAR $\gamma$ along with fucoidan could be helpful. EGR1 has also been reported to regulate the other gene in megakaryocytes. ${ }^{22}$ So, EGR1 could influence megakaryocytes with other substances as well as $\operatorname{PPAR} \gamma$

It has been reported that the expression of STC1 was strongly upregulated during megakaryocytic differentiation and accumulation of STC1 protein in normal megakaryocytes and platelet was observed. $^{23}$

CYP11B2 has been reported to be suppressed by PPAR $\gamma .{ }^{24} \mathrm{We}$ suggest there is a negative correlation between fucoidan and PPAR $\gamma$, but as we said earlier, the effect of PPAR $\gamma$ on megakaryocytes is not explained obviously, this correlation should be further studied. Functions of FCGR1 and YME1L1 in platelets are studied well, but their roles in megakaryocytes are not fully understood.

We couldn't have meaningful results with platelets. There are several studies reporting PPAR $\gamma$ ligand to have an inhibitory effect on platelet activation. And fucoidan has been reported possessing anticoagulant and antithrombotic actions. In our study, the ligand and antagonist of PPAR $\gamma$ showed no significant effects in mature platelets. Fucoidan significantly elevated the level of CD62p and CD63 and decreased PPAR $\alpha$ expression. With or without GW6471 or celecoxib, fucoidan increased COX-2 expression than control. In PTF-assay with T-TAS, GW6471 appeared to enhance thrombogenicity, whereas fucoidan appeared to suppress thrombogenicity. We guess the platelets isolated from discarded plateletpheresis products could have some limitations such as partial activation of platelets influencing the results.

Thrombocytopenia is a critical problem causing significant morbidity and mortality, and platelet transfusion is the most commonly used therapy but has limitations of alloimmunization, availability, and expense. In this study, we found that $15 \mathrm{~d}-\mathrm{PGJ}_{2}$ and fucoidan influence the development of megakaryocytes through regulation of PPAR $\gamma$ and genes including EGRI and STC1. This finding suggests the possibility of development of more safe and convenient method using the small molecules to treat thrombocytopenic patients.

The PPAR $\gamma$ ligand could enhance megakaryocytic maturation independent on PPAR $\gamma$, so studies for another mechanism of PPAR $\gamma$ ligand influencing megakaryocytes are needed. And the relationship between megakaryocytic differentiation and decrease of COX-2 expression by PPAR $\gamma$ ligand should be investigated further. Also, the hidden abilities of genes upregulated by fucoidan should be studied as well. In summary, these findings support PPAR ligand, and brown seaweed based compound plays a role in megakaryocytic differentiation even in genomic level.

\section{Conflict of interest}

No potential conflicts of interest relevant to this article were reported.

\section{Acknowledgments}

This work was supported by the National Research Foundation of Korea (NRF) grant funded by the Korea government (MSIP) (2018R1A1A3A04078765).

\section{References}

1. Morrell CN, Aggrey AA, Chapman LM, Modjeski KL. Emerging roles for platelets as immune and inflammatory cells. Blood 2014;123:2759-67.

2. Garraud O, Hamzeh-Cognasse H, Pozzetto B, Cavaillon JM, Cognasse F. Bench-to-bedside review: Platelets and active immune functions - new clues for immunopathology? Crit Care 2013;17:236.

3. Lannan KL, Sahler J, Kim N, Spinelli SL, Maggirwar $\mathrm{SB}$, Garraud O, et al. Breaking the mold: transcription factors in the anucleate platelet and platelet-derived microparticles. Front Immunol 2015;6:48.

4. Michalik L, Auwerx J, Berger JP, Chatterjee VK, Glass CK, Gonzalez FJ, et al. International Union of Pharmacology. LXI. Peroxisome proliferator-activated receptors. Pharmacol Rev 2006;58:726-41.

5. Kubota N, Terauchi Y, Miki H, Tamemoto H, Yamauchi T, Komeda K, et al. PPAR gamma mediates high-fat diet-induced adipocyte hypertrophy and insulin resistance. Mol Cell 1999;4:597-609.

6. Ricote M, Li AC, Willson TM, Kelly CJ, Glass CK. The peroxisome proliferator-activated receptor gamma is a negative regulator of macrophage activation. Nature 1998;391:79-82.

7. Rieusset J, Toure F, Michalik L, Escher P, Desvergne B Niesor E, et al. A new selective peroxisome proliferator-activated receptor gamma antagonist with antiobesity and antidiabetic activity. Mol Endocrinol 2002;16
2628-44.

8. Akbiyik F, Ray DM, Gettings KF, Blumberg N, Francis CW, Phipps RP. Human bone marrow megakaryocytes and platelets express PPARgamma, and PPARgamma agonists blunt platelet release of CD40 ligand and thromboxanes. Blood 2004:104:1361-8.

9. Moraes LA, Spyridon M, Kaiser WJ, Jones CI, Sage T, Atherton RE, et al. Non-genomic effects of PPARgamma ligands: inhibition of GPVI- stimulated platelet activation. J Thromb Haemost 2010;8:577-87.

10. O'Brien JJ, Ray DM, Spinelli SL, Blumberg N, Taubman MB, Francis CW, et al. The platelet as a therapeutic target for treating vascular diseases and the role of eicosanoid and synthetic PPARgamma ligands. Prostaglandins Other Lipid Mediat 2007;82:68-76.

11. Li D, Chen K, Sinha N, Zhang X, Wang Y, Sinha AK, et al. The effects of PPAR-gamma ligand pioglitazone on platelet aggregation and arterial thrombus formation. Cardiovasc Res 2005;65:907-12.

12. Greene ME, Pitts J, McCarville MA, Wang XS, Newport JA, Edelstein C, et al. PPARgamma: observations in the hematopoietic system. Prostaglandins Other Lipid Mediat 2000;62:45-73.

13. Nagasawa E, Abe Y, Nishimura J, Yanase T, Nawata H, Muta K. Pivotal role of peroxisome proliferator-activated receptor gamma (PPARgamma) in the regulation of erythroid progenitor cell proliferation and differentiation. Exp Hematol 2005;33:857-64.

14. O’Brien JJ, Spinelli SL, Tober J, Blumberg N, Francis $\mathrm{CW}$, Taubman MB, et al. 15-deoxy-delta12,14-PGJ2 enhances platelet production from megakaryocytes. Blood 2008;112:4051-60.

15. Forman BM, Tontonoz P, Chen J, Brun RP, Spiegelman BM, Evans RM. 15-Deoxy-delta 12, 14-prostaglandin $\mathrm{J} 2$ is a ligand for the adipocyte determination factor PPAR gamma. Cell 1995;83:803-12.

16. Li B, Lu F, Wei X, Zhao R. Fucoidan: structure and bioactivity. Molecules 2008;13:1671-95.

17. Jiao G, Yu G, Zhang J, Ewart HS. Chemical structures and bioactivities of sulfated polysaccharides from marine algae. Mar Drugs 2011;9:196-223.

18. Cumashi A, Ushakova NA, Preobrazhenskaya ME, D'Incecco A, Piccoli A, Totani L, et al. A comparative study of the anti-inflammatory, anticoagulant, antiangiogenic, and antiadhesive activities of nine differen fucoidans from brown seaweeds. Glycobiology 2007 17:541-52.

19. Ustyuzhanina NE, Ushakova NA, Zyuzina KA, Bilan MI, Elizarova AL, Somonova OV, et al. Influence of fucoidans on hemostatic system. Mar Drugs 2013;11: 2444-58.

20. Ackerman WE 4th, Zhang XL, Rovin BH, Kniss DA. Modulation of cytokine-induced cyclooxygenase two expressions by PPARG ligands through NFkappaB signal disruption in human WISH and amnion cells. Biol Reprod 2005;73:527-35

21. Nebbaki SS, El Mansouri FE, Afif H, Kapoor M, Benderdour M, Duval N, et al. Egr-1 contributes to IL1-mediated down-regulation of peroxisome proliferator-activated receptor $\gamma$ expression in human osteoar- 
thritic chondrocytes. Arthritis Res Ther 2012;14:R69.

22. Jalagadugula G, Dhanasekaran DN, Kim S, Kunapuli SP, Rao AK. Early growth response transcription factor EGR-1 regulates Galphaq gene in megakaryocytic cells. J Thromb Haemost 2006;4:2678-86.
23. Serlachius M, Alitalo R, Olsen HS, Andersson LC. Expression of stanniocalcin-1 in megakaryocytes and platelets. Br J Haematol 2002;119(2):359-63.

24. Uruno A, Matsuda K, Noguchi N, Yoshikawa T, Kudo $\mathrm{M}$, Satoh F, et al. Peroxisome proliferator-activated re- ceptor-\{gamma\} suppresses CYP11B2 expression and aldosterone production. J Mol Endocrinol 2011;46:3749. 